\title{
Futbolcularda Alt Ekstremiteye Uygulanan Akut Vibrasyon Antrenmanının Şut Hızı Şut İsabeti ve Çeviklik Performansı Üzerine Etkisinin İncelenmesi*
}

\author{
The Effect of Acute Vibration Training Applied to Lower Extremity of \\ Footballers on Shooting Speed, Shooting Accuracy and Agility Performance
}

\author{
ORİJINAL ARAŞTIRMA/ \\ ORIGINAL RESEARCH \\ Emrah ŞENGÜR ${ }^{1}$ \\ Zait Burak AKTUĞ $\breve{2 \dagger}^{2 \dagger}$ \\ Gürkan YILMAZ 3
}

${ }^{1}$ Niğde Ömer Halisdemir Üniversitesi, Sosyal Bilimler Enstitüsü. https://orcid.org/0000-0001-5092-2300 ${ }^{2}$ Niğde Ömer Halisdemir Üniversitesi https://orcid.org/0000-0002-5102-4331 ${ }^{3}$ Niğde Ömer Halisdemir Üniversitesi https://orcid.org/0000-0002-8292-2847

\section{$\ddot{O} z$}

$\mathrm{Bu}$ çalışmanın amacı, futbolcularda alt ekstremiteye uygulanan akut vibrasyon antrenmanın şut hızı, şut isabeti ve çeviklik performansı üzerine etkisinin incelenmesidir. Çalışmaya 18-25 yaş arasında 33 gönüllü amatör erkek futbolcu katılmıştır. Futbolcuların şut hızları radar aleti ile şut isabeti Mor-Christian futbol yetenek testi ile, çeviklik performansı Illinois çeviklik testi ile belirlenmiştir. Futbolcuların şut isabeti, şut hızı ve çeviklik performansları herhangi bir egzersiz uygulanmadan ve vibrasyon antrenmanı uygulandıktan sonra olmak üzere iki kez ölçülmüştür. Futbolcuların şut hızı, şut isabeti performansının ön test son test arasındaki farkı belirlemede Paired T Testi, çeviklik performanslarının ön test ve son testleri arasındaki farkı belirlemede Wilcoxon İşaretli Sıralar Testi uygulanmıştır. Elde edilen sonuçlara göre vibrasyon antrenmanı sonrası şut hızı, şut isabeti ve çeviklik performansının istatiksel olarak anlamlı şekilde geliştiği belirlenmiştir $(\mathrm{p}<0.05)$. Sonuç olarak, akut vibrasyon antrenmanının şut hızı, şut isabeti ve çeviklik performansını arttırdığg söylenebilir.

Anahtar kelimeler: Vibrasyon, Şut Hızı, Şut İsabeti, Çeviklik, Futbol
Yayın Bilgisi

Gönderi Tarihi: 19.11.2018

Kabul Tarihi: 29.05.2019

Online Yayın Tarihi: 30.06.2019

\begin{abstract}
The aim of this study is to examine the effects of acute vibration training applied to the lower extremity of footballers on shooting speed, shooting accuracy and agility performance. 33 voluntary amateur male soccer players between the ages of 18-25 participated in the study. The soccer players' shooting speed was determined with the radar tool. Shooting accuracy of the players was determined with the Mor-Christian Football Skill Test. Agility performance of the players was determined with the Illinois agility test. The players' shooting accuracy, shooting speed, and agility performances were measured twice: firstly without any exercise and then after the vibration training was applied. Paired T test was used to determine the difference between pretest and posttest scores of shooting speed and shooting accuracy. Wilcoxon signed ranks test was used to determine the difference between pretest and posttest scores of agility performance of the players. According to the obtained results, it was determined that the shooting speed, shooting accuracy and agility performance improved statistically significantly after the vibration training $(\mathrm{p}<0.05)$. As a result, acute vibration training has been shown to improve shooting speed, shooting accuracy and agility performance.
\end{abstract}

Key words: Vibration, Shooting Speed, Shooting Accuracy, Agility, Soccer

*Bu çalışma 31 Ekim-3 Kasım 2018 tarihleri arasında Antalya'da düzenlenen 16. Uluslararası Spor Bilimleri Kongresinde sözel bildiri olarak sunulmuştur.

† Sorumlu yazar: Zait Burak AKTUĞ, zaitburak@gmail.com 


\section{GİRIŞ̧}

Vibrasyon bir cismin dinlenik konumuna göre düzenli veya düzensiz olarak oluşturduğu periyodik hareketler sonucu meydana gelen mekanik yollu salınımlar olarak tanımlanmaktadır. Diğer bir değişle bir cismin pozitif ve negatif yöndeki en büyük yer değiştirmesi olarak tanımlanan vibrasyonun, genliği (salınımın büyüklüğünü) milimetre cinsinden, birim zamanda tamamlanan vibrasyon sayısı olarak tanımlanan vibrasyon frekansı ise Hertz $(\mathrm{Hz})$ cinsinden belirlenmektedir (Cardinale ve Bosco, 2003).

Vibrasyon sportif performansı arttırmak amacı ile ilk olarak 1980'li y1llarda Rusya'da kullanılmıştır. Kuvvet ve güç gelişimini geleneksel yöntemlerden farklı bir şekilde geliştirmek için Rus bilim adamları direnç egzersizlerini vibrasyon uygulamaları ile birleştirmişler ve bu yöntemi de vibrasyon antrenmanı olarak tanımlamışlardır (Issurin, Liebermann ve Tenenbaum, 1994). Vibrasyon antrenmanları kas iğciklerinin primer sonlanmalarının aktivasyonlarının artırmasına bağlı olarak kasta tonik vibrasyon refleksi oluşturmakta ve bu durumda kasılma gücünde artış meydana getirmektedir (Cardinale ve Bosco, 2003). Uygulanan vibrasyon antrenmanlarının kas iğciklerinin primer sonlanmalarının aktivasyonlarını artmasına bağlı olarak kasta kasılmaya katılan sarkomer sayısı artmaktadır. Bu durum kasın tonik vibrasyon refleksini oluşturmasını ve kaslar arasındaki ilişkiyi arttırmasını sağlamaktadır (Hagbarth ve Eklund, 1966).

Vibrasyon antrenmanlarının kısa ve uzun süreli etkileri olduğundan dolayı son zamanlarda çeşitli motorik özellikleri geliştirmek ve çeşitli performans değerlerini yükseltmek için birçok branşta kullanılmaktadır. Bu branşlardan bir tanesi de futboldur. Futbol, çeşitli becerilerin karışık halde uygulandığı bir spordur ve bu beceriler birbirleriyle etkileşim halindedir. Futbolda kullanılan becerilerden bir tanesi de çevikliktir. Çeviklik, bir noktadan diğerine hareket ederken vücudun yönünü mümkün olduğunca hızlı, akıc1, kolay ve kontrollü şekilde değiştirebilme yeteneğidir (Brown, Ferrigno ve Santana, 2000). Futbolda önemli olan diğer becerilerden bazıları da şut hızı ve şut isabetidir. Şut hızı, atış kuvvetini oluşturan eklemlerin hareket açıklığı ile doğrudan ilgilidir. Hareketten sorumlu agonist kaslar, hareketin başlangıcında geniş eklem hareketleriyle uyumlu olarak gerilebileceklerdir. Gerilmiş kasın kasılma gücü daha fazla olduğu gibi antagonist kasların da yeterli esneklikte olması, hareketin kolaylıkla gerçekleşmesine ve eklem hareketinin son derecesine kadar ulaşabilmesine imkan tanıyacaktır. Geniş eklem hareketi boyunca harekete 
katılan kas lifleri ve dolayısıyla sarkomer sayısı saha fazla olacağından kasılma kuvveti yükselecektir. Bu durum da atış hızını artıııı etki yapacaktır (Kepoğlu, İkizler ve Akan, 2001).

Vibrasyon antrenmanı üzerine çeşitli araştırmalar yapılmıştır. Kosova (2013), eskrimcilerde akut vibrasyon antrenmanının görsel (optik) reaksiyon zamanı üzerine etkilerini, Bayram (2015) tenisçilerde vibrasyon uygulamasının motorik özellikler üzerine etkilerini incelemiştir. Başka bir çalışmada Kizilin (2016) farklı branşlardaki sporculara uygulanan vibrasyon antrenmanının atış hızı ve mesafesine, Berk (2017) ise futbolcularda akut vibrasyon antrenmanın statik ve dinamik denge performansı üzerine etkilerini incelemiştir. Fakat litaretürde futbolculara uygulanan akut vibrasyon antrenmanın şut hızı, şut isabeti ve çeviklik performansı üzerine etkisini inceleyen bir çalışma bulunmamaktadır. Bu durum göz önüne alınarak yapılan çalışmanın amacı futbolculara uygulanan akut vibrasyon antrenmanın şut hızı, şut isabeti ve çeviklik performansı üzerine etkisinin incelenmesidir.

\section{YÖNTEM}

\section{Çalışma Grubu}

Araştırmaya Niğde ilinde amatör olarak futbol oynayan gönüllü 33 futbolcu katılmıştır. Çalışmaya katılan futbolcular, haftada en az 4 gün antrenman 1 gün müsabaka yapan sporculardan seçilmiştir. Birinci gün şut hızı ve şut yetenek testi ölçümlerinin, ikinci gün toplu ve topsuz illinois çeviklik testlerinin ön testleri ölçülmüştür. Son test (vibrasyon antrenman sonrası) ölçümlerinde her bir parametre ayrı günlerde uygulanmıştır. Her parametrenin ölçümü öncesi $10 \mathrm{dk}$ 1sınma yaptırılmıştır. Futbolculara vibrasyon antrenmanında 4 akut vibrasyon hareketi (Quadricep sağsol, Squat (basic squat), Calf Raise) uygulanmıştır. Futbolcuların vücut ağırlıkları, vücut kitle indeksleri (VKI), vücut yağ yüzdeleri (VYY), vücut yağ kütleleri (VYK) ve yağsız vücut ağırlıkları (YVA) Tanita BC 418 MA Profesyonel Segmental vücut analiz sistemi ile ölçülmüştür. 


\section{Verilerin Toplanması}

\section{Şut Hızı}

Şut hızını ölçmek için Stalker Solo 2 Sports Radar Gun marka tabanca radar aleti kullanılmıştır. Futbolculardan ayaküstü vuruş tekniği ile vuruş yapılması istenmiştir. Futbolculara hem ön testte hem de son teste 3' er kez olmak üzere toplam 6 vuruş yaptırılmış, en iyi değer çalışmaya dâhil edilmiştir (Şekil 1).

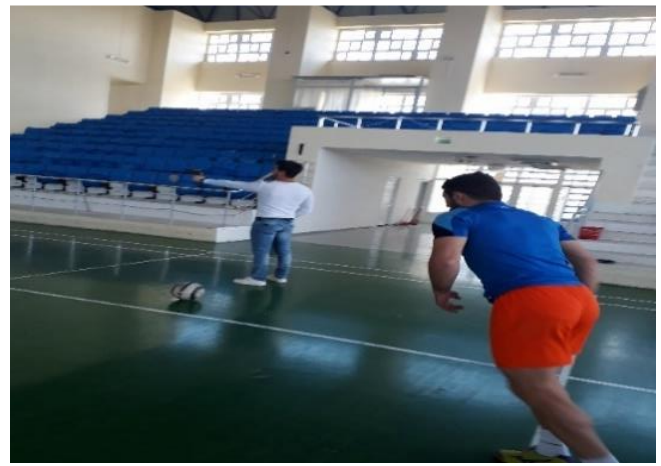

Şekil 1

\section{Şut Testi (Mor Christian Yetenek Testi)}

Şut yeteneği test istasyonları için 1.20 m çapındaki 4 daire şekil 3'deki gibi yerleştirilmiştir. Vuruş çizgisi kaleye paralel ve 14.5 m uzaklıktadır. Şut atma, vuruş çizgisinin gerisinde belirlenen hedefe doğru duran toplara vurarak yapılmıştır. İstenilen ayak kullanılabilmiş ve top vuruş çizgisinin gerisinde herhangi bir yere yerleştirilmiştir. 4 adet olan çember hedeflerin her birine 4'er kez olmak üzere toplam 16 kez vuruş yapılmıştır. Şut atmada doğru hedefe giden şutlara 10 puan, yanlış hedefe giden şutlara 4 puan verilmiştir (Strand ve Wilson, 1993) ( Şekil 2).

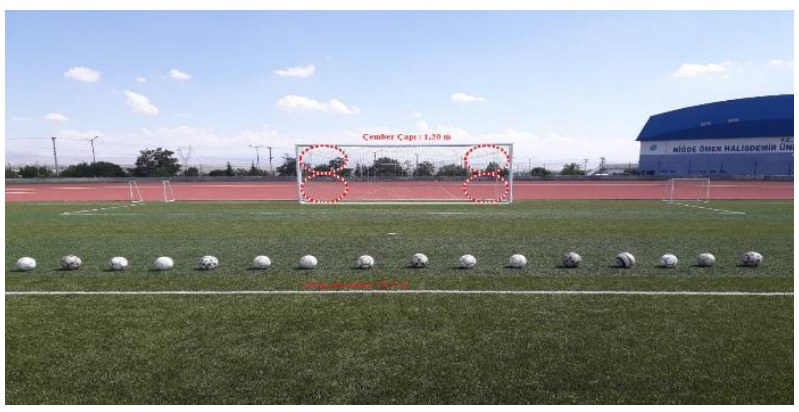

Şekil 2 


\section{Çeviklik (Illinois) Testi}

Bu test hem toplu hem de topsuz olmak üzere 2 farklı şekilde New Test 2000 marka fotosel aleti ile yapılmıştır. Test parkuru hazırlandıktan sonra testin başlangıç ve bitimine 0,01 sn hassasiyetle ölçüm yapan iki kapılı fotosel sistemi yerleştirilmiştir. Çalışmaya katılan futbolcu ayakta, başlangıç fotoselinin $1 \mathrm{~m}$ arkasındadır. Futbolcu isteği zaman koşuya başlamıştır. Sporcu başlangıç fotoselinden başlayıp okların takip ettiği yönde hareket edip, ikinci bitiş fotoselinde parkuru tamamlamıştır. Pistin uzunluğu $18 \mathrm{~m}$ olup, dönüş noktalarında 1,2 m arayla yerleştirilmiş 3 adet koni vardır. Orta bölümdeki konilerin arası 4,5 metredir (Miller, Herniman, Ricard ve Cheathamcc, 2006).

\section{Uygulanan Antrenman Metodu}

Çalışmada vibrayon antrenmanın şut hızı, şut isabeti ve çeviklik performansının akut etkisine bakılmıştır. Ölçüm yapılacak futbolculara ön test öncesinde $10 \mathrm{dk}$ 1sınma ve germe hareketleri yaptırılmıştır. Futbolculara şut yetenek testi (Mor Christian yetenek testi), şut hızı (vuruş hızı) ve çeviklik testi (illinois) uygulanmıştır. İlk gün şut hızı, şut yetenek testi ikinci gün ise toplu ve topsuz illinois çeviklik testinin ön testleri ölçülmüştür. Son test (vibrasyon antrenman sonrası) ölçümlerinde her bir parametre ayrı günlerde uygulanmıştır. Her bir parametre öncesinde futbolculara düşük yoğunluklu ısınma egzersizi uygulanmıştır. Isınma koşusundan sonra $2 \mathrm{dk}$ yürüyüş ile aktif dinlenme yapılmıştır. Akut sonuçlar amaçlandığı için tek bir vibrasyon uygulaması 4 farklı şekilde toplamda $120 \mathrm{sn}$ (her bir hareket için $30 \mathrm{sn}$ ) olarak uygulanmıştır. Uygulamaya başlanmadan önce tüm hareketler sporculara görsel olarak gösterilmiş ve anlatılmıştır. Vibrasyon antrenmanları arasında 30 sn dinlenme verilmiştir. Vibrasyon antrenmanı frekansı ve süresi ayarlanabilen DKN XG10 vibrasyon aletiyle gerçekleştirilmiştir. Alt ekstremiteye vibrasyon antrenmanı 4 farklı şekilde uygulanmıştır.

1. Qalf Raise: Futbolcu vibrasyon platformu üzerinde ayakucuna yükselmiş pozisyonda, dizler ve üst gövde düz olacak şekilde (30 sn süre ile $35 \mathrm{~Hz}$ şiddetinde) hareketi uygulamıştır (Şekil 3).

2. Squat (Basic Squat): Futbolcu vibrasyon platformu üzerinde ayak tabanları tamamen platformla temas halindeyken, dizler $90^{\circ}$ bükük ve üst ekstremite düz bir şekilde (30 sn süre ile $35 \mathrm{~Hz}$ şiddetinde) hareketi uygulamıştır (Şekil 4). 
3. Front Lunge (right): Futbolcu vibrasyon platformu üzerinde sağ dizi $90^{\circ}$ bükük, ayak tabanı tamamen vibrasyon tabanı üzerinde, sol ayağı zeminde olacak şekilde (30 sn süre ile $35 \mathrm{~Hz}$ şiddetinde) hareketi uygulamıştır (Şekil 5).

4. Front Lunge (left): Futbolcu vibrasyon platformu üzerinde sol dizi $90^{\circ}$ bükük, ayak tabanı tamamen vibrasyon tabanı üzerinde, sağ ayağı zeminde olacak şekilde (30 sn süre ile $35 \mathrm{~Hz}$ şiddetinde) hareketi uygulamıştır (Şekil 6).
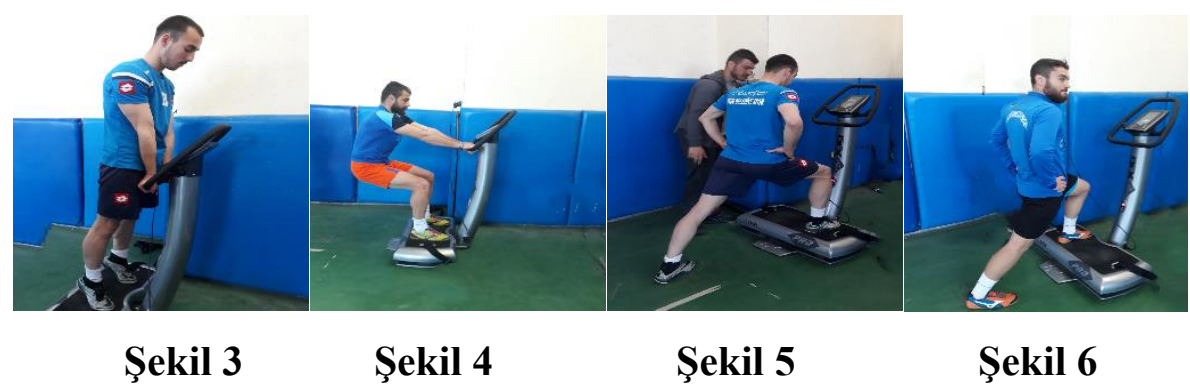

\section{Verilerin Analizi}

Verilerin analizinde SPSS 24 paket programı kullanılmıştır. Verilerin normallik dağılımını Shapiro-Wilk testi ile belirlenmiştir. Normal dağılım gösteren şut hızı, şut isabeti ve topsuz illinois testlerinde verilerin ön test-son test karşılaştırılması için Paired T Testi, normal dağılım göstermeyen toplu illinois verileri için ön test-son test karşılaştırılmasında Wilcoxon İşaretli Sıralar Testi kullanılmıştır. Çalışmada anlamlılık düzeyi $\mathrm{p}<0,05$ olarak kabul edilmiştir.

\section{BULGULAR}

Tablo 1. Futbolculara ait demografik değişkenlerin tanımlayıcı istatistikleri

\begin{tabular}{|c|c|c|c|}
\hline Değişken & $\mathbf{N}$ & $\bar{x}$ & Ss \\
\hline Yaş (yıl) & 33 & 20,48 & 2,27 \\
\hline Spor Yaşı (yıl) & 33 & 6,73 & 2,14 \\
\hline Boy (m) & 33 & 1,75 & 0,06 \\
\hline Kilo (kg) & 33 & 68,94 & 8,04 \\
\hline VKİ $\left(\mathrm{kg} / \mathrm{m}^{2}\right)$ & 33 & 22,10 & 1,95 \\
\hline $\operatorname{VYY}(\%)$ & 33 & 9,12 & 3,84 \\
\hline VYK (kg) & 33 & 6,46 & 3,13 \\
\hline YVA $(\mathrm{kg})$ & 33 & 61,81 & 5,09 \\
\hline
\end{tabular}

ortalaması 1,75 m., kilo ortalaması $68,74 \mathrm{~kg}$, VKİ ortalaması 22,10 kg/m², VYY ortalaması 9,12(\%), VYK ortalaması 6,46 kg, VYA ortalaması $61,81 \mathrm{~kg}$ olarak belirlenmiştir. 
Şengür, E., Aktuğ, Z.B., ve Yılmaz, G. (2018). Futbolcularda alt ekstremiteye uygulanan akut vibrasyon antrenmanının şut hızı şut isabeti ve çeviklik performansı üzerine etkisinin incelenmesi. CBÜ Beden Ĕ̈itimi ve Spor Bilimleri Dergisi, 14(1), 56-65.

Tablo 2. Futbolcuların şut hızlarının eşli gruplar şeklinde karşılaştırıldığı t testi

\begin{tabular}{|c|c|c|c|c|c|c|c|c|c|}
\hline \multirow[b]{2}{*}{ Değișken } & \multirow[b]{2}{*}{ Eşli Grup } & \multirow[b]{2}{*}{$\mathbf{N}$} & \multirow[b]{2}{*}{$\bar{x}$} & \multirow[b]{2}{*}{ Ss } & \multicolumn{2}{|c|}{ İkili Arasındaki Farklar } & \multirow[b]{2}{*}{$\mathbf{t}$} & \multirow[b]{2}{*}{ df } & \multirow[b]{2}{*}{$\mathbf{p}$} \\
\hline & & & & & $\bar{x}$ & Ss & & & \\
\hline \multirow{2}{*}{ Şut Hızı $(\mathrm{km} / \mathrm{s})$} & Ön Test & 33 & 93,77 & 7,60 & \multirow{2}{*}{$-3,95$} & \multirow{2}{*}{3,47} & \multirow{2}{*}{$-6,53$} & \multirow[b]{2}{*}{32} & \multirow{2}{*}{$0,00^{*}$} \\
\hline & Son Test & 33 & 97,72 & 6,84 & & & & & \\
\hline
\end{tabular}

Tablo 2'de futbolcuların şut hızlarının eşli gruplarına ilişkin karşılaştırılmasını göstermektedir. Futbolcuların eşli grupları incelendiğinde şut hızlarının ortalamaları ön testte $93.77 \mathrm{~km} / \mathrm{s}$, son testte ise $97.72 \mathrm{~km} / \mathrm{s}$ olduğu tespit edilmiştir. Futbolcuların ortalamaları arasında anlamlı bir farklılık olduğu belirlenmiştir $[\mathrm{t}(33)=-6.53 ; \mathrm{p}<0.05]$.

Tablo 3. Futbolcuların şut yetenek testinin eşli gruplarının karşılaştırıldığg $\mathrm{t}$ testi

\begin{tabular}{|c|c|c|c|c|c|c|c|c|c|}
\hline \multirow[b]{2}{*}{ Değişken } & \multirow[b]{2}{*}{ Eşli Grup } & \multirow[b]{2}{*}{$\mathbf{N}$} & \multirow[b]{2}{*}{$\bar{x}$} & \multirow[b]{2}{*}{ Ss } & \multicolumn{2}{|c|}{ İkili Arasındaki Farklar } & \multirow[b]{2}{*}{$\mathbf{t}$} & \multirow[b]{2}{*}{ df } & \multirow[b]{2}{*}{$\mathbf{p}$} \\
\hline & & & & & $\bar{x}$ & Ss & & & \\
\hline \multirow{2}{*}{$\begin{array}{l}\text { Şut Yeteneği } \\
\quad \text { (puan) }\end{array}$} & Ön Test & 33 & 42,48 & 16,30 & \multirow{2}{*}{$-20,18$} & \multirow{2}{*}{12,40} & \multirow{2}{*}{$-9,35$} & \multirow{2}{*}{32} & \multirow{2}{*}{$0,00^{*}$} \\
\hline & Son Test & 33 & 62,67 & 16,81 & & & & & \\
\hline
\end{tabular}

Tablo 3'te futbolcuların şut yeteneklerinin eşli gruplarına ilişkin karşılaştırılması gösterilmektedir. Futbolcuların eşli grupları incelendiğinde, şut yetenekleri ortalamaları ön testte 42.48 puan, son testte ise 62.67 puan olarak bulunmuştur. Futbolcuların ortalamaları arasında anlamlı bir farklılık olduğu tespit edilmiştir $[\mathrm{t}(33)=-9.35 ; \mathrm{p}<0.05]$.

Tablo 4. Futbolcuların Illinois testinin eşli gruplarının karşılaştırıldı̆̆

\begin{tabular}{|c|c|c|c|c|c|c|c|c|c|}
\hline \multirow[b]{2}{*}{ Değişken } & \multirow[b]{2}{*}{ Eşli Grup } & \multirow[b]{2}{*}{$\mathbf{N}$} & \multirow[b]{2}{*}{$\bar{x}$} & \multirow[b]{2}{*}{ Ss } & \multicolumn{2}{|c|}{ İkili Arasındaki Farklar } & \multirow[b]{2}{*}{$\mathbf{t}$} & \multirow[b]{2}{*}{ df } & \multirow[b]{2}{*}{$\mathbf{p}$} \\
\hline & & & & & $\overline{\bar{x}}$ & Ss & & & \\
\hline \multirow{2}{*}{$\begin{array}{l}\text { Illinois } \\
\text { Testi (ms) }\end{array}$} & Ön Test & 33 & 17968,24 & 988,01 & \multirow{2}{*}{658,67} & \multirow{2}{*}{538,67} & \multirow{2}{*}{7,03} & \multirow{2}{*}{32} & \multirow{2}{*}{$0,00^{*}$} \\
\hline & Son test & 33 & 17309,52 & 871,06 & & & & & \\
\hline
\end{tabular}

Tablo 4 futbolcuların topsuz yapılan Illinois çeviklik testinin eşli gruplarına ilişkin karşılaştırılmasını göstermektedir. Futbolcuların eşli grupları incelendiğinde, Illinois test ortalamaları ön testte 17968.24 ms, son testte 17309.52 ms olarak tespit edilmiştir. Futbolcuların ortalamaları arasında anlamlı bir farklılık olduğu belirlenmiştir [t(33)=7.03; $\mathrm{p}<0.05]$. 
Şengür, E., Aktuğ, Z.B., ve Yılmaz, G. (2018). Futbolcularda alt ekstremiteye uygulanan akut vibrasyon antrenmanının şut hızı şut isabeti ve çeviklik performansı üzerine etkisinin incelenmesi. CBÜ Beden Ĕ̈itimi ve Spor Bilimleri Dergisi, 14(1), 56-65.

Tablo 5. Futbolcuların toplu Illinois testinin eşli gruplarına ilişskin işaretli sıralar testi

\begin{tabular}{lcccccc}
\hline \multicolumn{1}{c}{ Değişken } & $\begin{array}{c}\text { Eşli } \\
\text { Grup }\end{array}$ & $\mathbf{N}$ & $\overline{\boldsymbol{x}}$ & Ss & $\mathbf{Z}$ & $\mathbf{p}$ \\
\hline Toplu Illinois & Ön Test & 33 & 23504,03 & 2228,55 & & \\
Testi (ms) & Son Test & 33 & 22020,48 & 2082,15 & & $0,00^{*}$ \\
\hline
\end{tabular}

Tablo 5 futbolcuların toplu Illinois testi eşli gruplarının (ön test - son test) Wilcoxon İşaretli

Sıralar Toplamı Testi ile karşılaştırılmasını göstermektedir. Tablo incelendiğinde futbolcuların toplu Illinois testinde ön test ve son test arasında anlamlı bir fark olduğu bulunmuştur $[Z(33)=$ $4.529, \mathrm{p}<0.05]$. Fark olan sürelerin ortalamaları incelendiğinde bu farkın son test lehine olduğu görülmektedir.

\section{TARTIŞMA VE SONUÇ}

Yapılan çalışmada futbolcuların şut hızları ortalamalarının ön testte $93.77 \mathrm{~km} / \mathrm{s}$, son testte (vibrasyon antrenmanı sonrası) ise $97.72 \mathrm{~km} / \mathrm{s}$ olduğu tespit edilmiştir. Futbolcuların şut hızlarının son testte istatiksel olarak anlamlı şekilde arttığ 1 belirlenmiştir $(\mathrm{p}<0.05)$. Kizilin (2016) yaptığ çalışmada akut vibrasyon antrenmanın atış hızını geliştirdiğini bulurken, diğer bir çalışmada vibrasyon egzersizlerinin şut hızı ve topu uzağa atma değerlerinde önemli ölçüde gelişim sağladığı tespit edilmiştir (Bunker, Rhea, Simons ve Marin, 2011). Başka bir çalışmada ise Chih ve Ying (2015) tüm vücut vibrasyon eğitiminin şut hızı, hareket hızı ve atlama performanslarını geliştirdiği sonucuna varmıştır. Yukarıda belirtilen çalışmaların sonuçları bizim çalışmamızdaki vibrasyon egzersizlerinin şut hızını geliştirmesini destekler niteliktedir. Bu durum uygulanan vibrasyon antrenmanlarının kas iğciklerinin primer sonlanmalarının aktivasyonlarını artırmasına bağlı olarak kasta tonik vibrasyon refleksini oluşturması ve bu durumun da kasılma gücünde artış meydana getirmesi ile ilişkili olabilir (Cardinale ve Bosco, 2003).

Futbolcuların şut isabeti ortalamaları ön testte 42.48 puan, son testte (vibrasyon antrenmanı sonrası) ise 62.67 puan olarak bulunmuştur. Futbolcuların şut isabetlerinin son testte istatiksel olarak anlamlı şekilde arttığı belirlenmiştir $(\mathrm{p}<0.05)$. Soylu, Gelen ve Yı1dız (2012) vibrasyon antrenmanlarının futbol penaltı atış performansını arttırdığını ve en iyi etkinin $30 \mathrm{~Hz}$ ve $35 \mathrm{~Hz}$ frekans aralığında gerçekleştiğini belirtmiştir. Başka bir çalışmada ise Ebrem ve ark., (2008) vibrasyon antrenmanlarının hentbolcularda atış performansını olumlu şekilde geliştirdiğini 
belirlemiştir. Yukarıda belirtilen çalışmaların sonuçları bizim çalışmamızdaki vibrasyon egzersizlerinin şut isabetini geliştirmesini destekler niteliktedir.

Uygulanan vibrasyon antrenmanları kas iğciklerinin primer sonlanmalarının aktivasyonlarının artmasına bağlı olarak kasta kasılmaya katılan sarkomer sayısını arttırmaktadır. $\mathrm{Bu}$ durum kasın tonik vibrasyon refleksini oluşturması ve kaslar arası ilişkiyi arttırmasını sağlamaktadır (Hagbarth ve Eklund, 1966). Bu bilgiler göz önüne alınarak uygulanan akut vibrasyon antrenmanlarının şut isabeti performansına olumlu katkı sağlayacağı söylenebilir.

Futbolcuların topsuz illinois test ortalamaları ön testte 17968,24 ms, son testte (vibrasyon antrenmanı sonrası) 17309,52 ms olarak tespit edilirken, toplu illinois test ortalamaları ön testte 23504,03 ms, son testte (vibrasyon antrenmanı sonrası) 22020,48 ms olarak bulunmuştur. Futbolcuların illinois test normlarına göre topsuz illinois test sonuçlarının ortalama düzeyde olduğu belirlenmiştir. Futbolcuların hem toplu hem de topsuz çeviklik performanslarının son testte istatiksel olarak anlamlı şekilde geliştiği tespit edilmiştir $(\mathrm{p}<0.05)$.

Literatür incelendiğinde, vibrasyon antrenmanlarının çeviklik performansı üzerine etkilerinin incelendiği çalışmalarda farklı sonuçların olduğu görülmektedir. Andrija, Martin ve Vladimir (2015) vibrasyon antrenmanlarının çeviklik performansı üzerinde herhangi bir katkısının olmadığını söylemiştir. Benzer bir çalışmada Darryl, Stephen ve Michael (2004) sporcu olmayan 16 erkek, 8 kadın toplam 24 kişiye uygulanan 26 Hz'lik tüm vücut vibrasyon antrenmanının yatay sıçrama, sprint ve çeviklik performansı üzerinde bir katkısı olmadığını belirtmiştir. 17 hokeyci üzerinde yapılan başka bir çalışmada $35 \mathrm{~Hz}$ 'lik kısa süreli tüm vücut vibrasyon antrenmanının çeviklik performansını geliştirmediği tespit edilmiştir (Pienaar, 2010). Benzer bir çalışmada Torvinen et al. (2002) 16 kişiye uygulanan 15 Hz ve 30 Hz'lik akut vibrasyon egzersizinin çeviklik performansı üzerinde bir katkısı olmadığını söylemiştir.

Literatürde çalışmamızın sonucunu destekler nitelikte vibrasyon antrenmanlarının çeviklik performansı üzerine olumlu etkisinin olduğunu belirten çalışmalar da mevcuttur. Chin, Chi, Kuo, Chun, Ke (2016) yaptıkları çalışmada vibrasyon antrenmanlarının erkek voleybolcularda çeviklik, hız ve güç performansını önemli şekilde geliştirdiğini belirlemiştir. 21 erkek kolej futbolcusu üzerinde yapılan benzer bir çalışmada, akut vibrasyon egzersizlerinin sürat ve çeviklik performansını geliştirdiği belirlenmiştir (Jeffrey ve ark., 2013). 19 kişi üzerinde yapılan başka bir 
çalışmada 8 haftalık tüm beden vibrasyon antrenmanının çeviklik performansını geliştirdiği söylenmiştir (Bayram, 2015).

Akut ve kronik vibrasyona maruz kaldıktan sonra kuvvet üretme kapasitesinde bir artış meydana gelir. Gerilme reflekslerinin duyarlılığındaki artış ve beynin spesifik bölgelerinin uyarılması, nöromüsküler sistemin eksitatör durumunu belirler. Merkezi etki, spesifik hormonların salgılanmasını tetikleyen hipotalamus-hipofiz eksenini de etkiler. Tüm bu faktörler, iskelet kasının kuvvet üretme kapasitesindeki artışa katkıda bulunur. Çeviklik performansında da kuvvetin önemli bir faktör olması vibrasyon antrenmanlarının çeviklik performansı üzerinde etkili olduğunu düşündürmektedir (Cardinale ve Bosco, 2003).

Sonuç olarak, litaretürde akut vibrasyon antrenmanlarının farklı branşlara ait beceriler ve farklı motorik özellikler üzerine olan etkilerinin incelendiği çalışmalar bulunmasına rağmen, futbolcuların şut hızı, şut isabeti üzerine yapılan bir çalışma bulunmamaktadır. Bu durum göz önüne alınarak yapılan bu çalışmanın sonucunda, futbolculara uygulanan alt ekstremite akut vibrasyon antrenmanlarının şut hızı, şut isabeti ve çeviklik performansına önemli düzeyde katkı sağladığı belirlenmiştir.

\section{KAYNAKLAR}

Andrija, A., Georgiev, M., \& Mutavdzić, V. (2015). The impact of vibration traning on the whole body, explosive leg strength, speed and agility in basketball players aged 14-15. Research in Kinesiology, 43(1), 33-37.

Bayram, İ. (2015). Tüm beden vibrasyonunun bazı tenis performans parametreleri üzerine etkisi. Yüksek Lisans Tezi, Anadolu Üniversitesi Sağlık Bilimleri Enstitüsü, Eskişehir.

Berk, Y. (2017). Futbolcularda alt ekstremiteye uygulanan akut vibrasyon antrenmanın denge ve hız üzerine etkisi. Yüksek Lisans Tezi, Erciyes Üniversitesi Sağlık Bilimler Enstitüsü, Kayseri.

Brown, L.E., Ferrigno, V.A., \& Santana, J.C. (2000). Training for speed, agility and quickness. Champaign IL: Human Kinetics.

Bunker, D., Rhea, M., Simons, T., \& Marin, P. (2011). The use of whole-body vibration as a golf warm-up. Journal Strength and Conditioning Research, 25(2), 293-297.

Cardinale, M., \& Bosco, C. (2003). The use of vibrations as an exercise intervention. Exercise and Sport Sciences Reviews, 31(1), 37.

Chih, C.S. \& Ying, C.S. (2015). Effects of eight weeks of whole-body vibration training on shooting speed and movement speed and decuple jump performance of young male handball players. International Journal of Medical and Health Sciences, 40, 3145 . 
Şengür, E., Aktuğ, Z.B., ve Yılmaz, G. (2018). Futbolcularda alt ekstremiteye uygulanan akut vibrasyon antrenmanının şut hızı şut isabeti ve çeviklik performansı üzerine etkisinin incelenmesi. CBÜ Beden Ĕ̈itimi ve Spor Bilimleri Dergisi, 14(1), 56-65.

Chin, S.H., Chi,Y., C., Kuo. C., L., Chun. H., C. \& Ke, C. (2016). The Acute effect of whole body vibration training on agility, speed and power in male volleyball players. 34. International Conference on Biomechanics in Sports, July 18-22.

Darryl, J.C., Stephen, J.L. \& Michael J.H. (2004). The short-term effect of whole-body vibration trainıng on vertical jump, sprint, and agility performance. Journal of Strength and Conditioning Research, 18(4), 828-832.

Ebrem, Ş., Gelen, E., Saygın, Ö., Karacabey, K., Kılınç, F., Polat, Y., ve ark. (2008). The accute effects of vibration on handball throw performance. in 10. International sport Sciences Congress. Bolu, Turkey.

Hagbarth, K.E. \& Eklund, G. (1966). Tonic vibration reflexes (TVR) in spasticity. Experimental Neurology, 2(2), 201-203.

Issurin, V.B., Liebermann, D.G. \& Tenenbaum, G. (1994). Effect of vibratory stimulation training on maximal force and flexibility. Journal of Sports Sciences, 12(6), 561-566.

Jeffrey, C.P., Haris, P., Fuad B., Edin, U., Melika, M. \& Mario, T. (2013). Acute effects of loaded whole body vibration schemes on counter movement jump, speed and agility. Turkish Journal of Sport and Exercise, 15(3), 56-59.

Kepoğlu, A., İkizler, C. ve Akan, İ. (2001). Hentbol sporu ile uğraşanların psikolojik antrenman hakkındaki bilgi ve tutumları. 11 13 Ekim 2001 II. Uluslararasi İzmir Spor Psikolojisi Sempozyumu.

Kizilin, M.A. (2016). Titreşim antrenmanlarının atış hızına akut etkisinin incelenmesi. Yüksek Lisans Tezi, Erciyes Üniversitesi Sağlık Bilimleri Enstitüsü, Kayseri.

Kosova, S. (2013). Eskrimcilerde akut vibrasyon uygulamasın görsel(optik) reaksiyon zamanı üzerine etkileri. Yüksek Lisans Tezi, Dokuz Eylül Üniversitesi Sağlık Bilimleri Enstitüsü, İzmir.

Miller, M., Herniman, J., Ricard, M. \& Cheathamcc, M.T. (2006). The effects of a 6-week plyometric training program on agility. Journal of Sports Science and Medicine, 5(3), 459-465.

Pienaar, C. (2010). The acute effect of whole body vibration (WBV) training on power-related measurements of field hockey players: biokinetics and sport science. African Journal Physical Health Education, Recreation and Dance, 16(4), 594-604.

Soylu, Ş., Gelen, E. ve Yıldız, S. (2012). The acute affect of vibration applications on jumping performance. International Journal of Human Sciences, 9(2), 1684-1690.

Strand, B.N. \& Wilson, R. (1993). Assessing sport skills. USA Utah State Un.: Human Kinetics Publishers.

Torvinen, S., Sievanen, H., Jarvinen, T.A., Pasanen, M., Kontulainen S., Jarvinen TL. et al. (2002). Effect of a vibration exposure on muscular performance and body balance. Randomized cross-over study. Clinical Physiology and Functional Imaging, $22(2), 145-152$. 